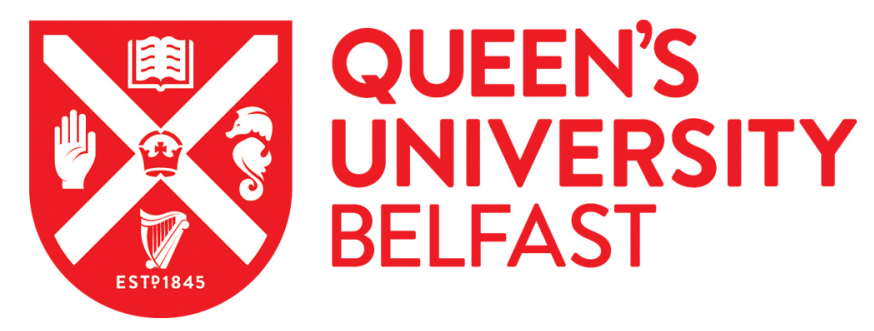

\title{
Stress, coping and satisfaction in nursing students
}

Gibbons, C., Dempster, M., \& Moutray, M. (2011). Stress, coping and satisfaction in nursing students. Journal of Advanced Nursing, 67(3), 621-632. https://doi.org/10.1111/j.1365-2648.2010.05495.x

Published in:

Journal of Advanced Nursing

Document Version:

Peer reviewed version

Queen's University Belfast - Research Portal:

Link to publication record in Queen's University Belfast Research Portal

\section{Publisher rights}

Copyright 2010 Blackwell Publishing.

This work is made available online in accordance with the publisher's policies. Please refer to any applicable terms of use of the publisher.

\section{General rights}

Copyright for the publications made accessible via the Queen's University Belfast Research Portal is retained by the author(s) and / or other copyright owners and it is a condition of accessing these publications that users recognise and abide by the legal requirements associated with these rights.

Take down policy

The Research Portal is Queen's institutional repository that provides access to Queen's research output. Every effort has been made to ensure that content in the Research Portal does not infringe any person's rights, or applicable UK laws. If you discover content in the Research Portal that you believe breaches copyright or violates any law, please contact openaccess@qub.ac.uk. 
Title page

Stress, coping and satisfaction in nursing students

Correspondence to C. Gibbons:

e-mail: c.gibbons@qub.ac.uk

First author

Chris Gibbons MSc PhD RN

Research Fellow

School of Nursing and Midwifery, Queen's

University Belfast, UK

Second author

Martin Dempster BSc MSc PhD

Lecturer

School of Psychology, Queen's University

Belfast, UK

Third author

Marianne Moutray RN RMN RCNT

Associate Head of School, Director of

Education (Nursing)

School of Nursing and Midwifery, Queen's

University Belfast, UK

This paper was not supported by any external funding and there are no conflicts of interest. 


\section{ABSTRACT}

Aim. This paper is a report of a study conducted to explore the relationship between sources of stress and psychological well-being and to consider how different sources of stress and coping resources might function as moderators and mediators on wellbeing.

Background. In most research exploring sources of stress and coping in nursing students stress has been construed as psychological distress. Sources of stress likely to enhance well-being and, by implication, learning have not been considered.

Method. A questionnaire was administered to 171 final year nursing students in 2008. Questions were asked to measure sources of stress when rated as likely to contribute to distress (a hassle) and rated as likely to help one achieve (an uplift). Support, control, self-efficacy and coping style were also measured, along with their potential moderating and mediating effects on well-being, operationalised using the General Health Questionnaire and measures of course and career satisfaction. Findings. Sources of stress likely to lead to distress were more often predictors of well-being than were sources of stress likely to lead to positive, eustress states, with the exception of clinical placement demands. Self-efficacy, dispositional control and support were important predictors, and avoidance coping was the strongest predictor of adverse well-being. Approach coping was not a predictor of well-being. The mere presence of support appeared beneficial, as well as the utility of that support to help a student cope.

Conclusion. Initiatives to promote support and self-efficacy are likely to have immediate benefits for student well-being. In course reviews, nurse educators need to consider how students' experiences might contribute not just to potential distress, but also to eustress.

Keywords: stress, coping, eustress, nursing education, survey, satisfaction 


\section{What is already known about this topic}

Researchers into stress in nursing students frequently use the term stress to denote psychological distress.

Sources of stress likely to enhance well-being and, by implication, learning have not been considered in previous research

The moderating and mediating effects between sources of stress and coping measures have not been considered in previous research.

\section{What this paper adds}

Measuring course demands rated as sources of eustress as well as distress increases the opportunity to identify the key components in effective learning in nurse education.

From the range of coping resources available, those that look to bolster self-efficacy, control and support are likely to be most beneficial in student learning.

\section{Implications for Practice and/or Policy}

Initiatives to promote support and self-efficacy are likely to have immediate benefits for student well-being.

In course reviews, nurse educators need to consider how students' experiences might contribute not just to potential distress, but also to eustress.

Student coping should be developed through the psychology component of nursing programmes and through standalone initiatives, and should consider the coping mechanisms that not only reduce distress but which increase eustress opportunities. 


\section{INTRODUCTION}

Stress can be the result of 'too much or too little arousal resulting in harm to mind and body' (Schafer 1992, p. 14). There is a growing body of evidence on stress among nurses and nursing students and its effect on well-being (Parkes 1994, Beck \& Srivastava 1991, Heaman 1995, Jones \& Johnston 1997, 1999).

\section{BACKGROUND}

Some of the sources of stress experienced by nursing students are experienced by students generally. Sources of academic stress include examinations and assessments (Howard, 2001; Kipping, 2000) and the timing of examinations has a particular impact on the work-life balance of female students with children. The latter is more common among nursing students compared to other students (Pryjmachuk \& Richards, 2007). In relation to workload, nursing students also experience longer hours of study and an associated lack of free time (Jones \& Johnston, 1997; Lo, 2002; Mahat, 1998).

The main sources of stress relate to experiences on placement. Some of these are common to those reported by practising nurses, such as working with dying patients; conflicts with other staff; insecurity about clinical competence; interpersonal problems with patients; and work overload (Rhead, 1995; Snape \& Cavanagh, 1995). Additional stressors faced by nursing students include developing clinical skills and, more broadly, a perceived lack of practical skills (Mahat, 1996, 1998). Time pressures within which they are expected to operate on placement, together with evaluations of clinical experience, are frequently reported (Jack, 1992). Status as a student on placement has been reported, and aligned to this are nursing staff attitudes towards students on placement (Kirkland 1998; Howard, 2001). Initial placements also produce disproportionate anxiety (Jack 1992).

\section{Coping with stress}

In Lazarus and Folkman's (1984) Transactional model of stress, the primary appraisal refers to the initial perception about a stressor and whether it is judged to be positive (leading to eustress), negative (leading to distress) or benign. The secondary appraisal refers to the coping responses the individual draws on. Interacting between the perception of stressors and the individual's response are a number of moderators. 
These include self-efficacy (Schaubroeck \& Merritt 1997 \& Lo, 2002); perceived control, support and coping style (Folkman, 1997; Van Der Doef \& Maes, 1999).

Lazarus and Folkman (1987) identified two types of coping - problem- and emotionbased. Both can be used to effect, but emotion-based coping is more frequently expressed in ineffective ways. Ceslowitz (1989) found a beneficial effect on clinical performance and the health consequences of stress as a result of problem-based coping, and others claim similar benefits for nursing student learning, performance and well-being (Lindop, 1999; Tully, 2004). Chang et al. (2006) summarise evidence that emotion-focused coping is more likely to be detrimental to health, and Lambert et al. (2004), found that escape-avoidance coping correlated with reduced mental health in a sample of Japanese nurses.

Lo (2002) explored stress and coping in over 100 Australian and New Zealand nursing students in a three-year longitudinal study. As well as finding similar results to Chang et al. on coping, Lo found that friends, family and spouses or partners were important sources of emotional support and often, with family and spouses, financial support too. Payne (2001) claimed that support available rather than type of coping used was the strongest predictor of nurses' well-being. Lucas et al. (1993) attributed the low psychological distress and high job satisfaction among nurses working on intensive and critical care units to the level of support available. This, in turn, was attributable to the nature of the work. Other researchers also claim a beneficial effect among nurses who have a strong sense of control in the work they do, Boey (1999), for example, found that nurses in Singapore who scored high on well-being reported strong internal locus of control, although they were also much more likely to report strong family support.

As with control, support and coping behaviour, students high in self-efficacy are much more likely to achieve in their academic and clinical work (Laschinger, 1996; Andrew, 1998). However, it is important to note that self-efficacy, as well as being a dispositional attribute, is a quality affected by experience. Greenglass and Burke (2000), for example, found that nurses working in Canadian hospitals undergoing change were much more likely to report a strong sense of self-efficacy if they believed that they had been adequately consulted and informed on the need for 
change, compared to those nurses who believed they had not. It is possible, however, that it was the self-efficacy characteristic that affected how those changes were appraised, rather than variations in how different managers introduced the changes affecting self-efficacy. In short, a causal relationship cannot be assumed, as measures of support, control, coping style and self-efficacy are likely to be affected by, as well as to affect, what is perceived as a source of stress and, in turn, the kind of impact it has on well-being.

Wu et al., (2007) explored the relationship between burnout and professional efficacy in 495 nurses in China. This is one of the few studies in which these different coping resources and moderators were considered. An inverse relationship was found between control and emotional exhaustion. Younger nurses were more likely to report burnout, and those low in educational status were more likely to report low professional efficacy. Interestingly, control, support and coping style were strong predictors not just of burnout, but also of professional efficacy.

\section{Measuring stress}

Many of the inventories used to measure sources of stress in nursing students have been accused of not being psychometrically rigorous (Jones \& Johnston, 1999). Moreover, what is common to all existing inventories exploring sources of stress (including the Beck and Srivastava (1991) Stress Inventory; Expanded Nursing Stress Scale (Clark \& Ruffin, 1992); Student Nurse Stress Inventory (Jones \& Johnston, 1999) and the Stress in Nursing Students questionnaire, (Deary et al 2003) is that they ask respondents to rate a range of stressors in terms of the extent to which they are distressing. The assumption is that, if course and placement experiences are reported as less distressing, then students' well-being, insofar as it is caused by the demands of the course, will be healthier and they will learn more. Such an approach ignores the fact that those stressors may, at different times, contribute to eustress or a level of stress that enhances performance. Deary et al, (2003), for example, measured burnout and stress in nursing students and found increased perceived stress combined with increased levels of personal achievement, suggesting that stress experiences can contribute to eustress. 
Gibbons et al. (2009a) developed and tested an inventory on sources of stress in nursing students. This instrument required respondents to rate sources of stress twice once in terms of their potential to cause distress (a hassle) and once in terms of their potential to help the person to achieve (an uplift). An exploratory factor analysis revealed that the sources of stress were grouped into three factors: Learning and teaching, Placement-related and Course organization. Nursing students reporting caseness on the General Health Questionnaire, or who were at risk of developing a transient stress related illness, did not report sources of stress as more distressing than those not reporting caseness, but did rate those sources of stress as providing far fewer opportunities to achieve. This finding challenges the traditional view that reducing distress will improve well-being; rather, what is more important is perceiving opportunities to achieve. Such a result questions the assumption that stress denotes psychological distress, a conception common to much earlier research.

\section{The United Kingdom context}

Across a range of professions, nurses top the league table for female suicides (Hawton et al. 2002). The profession has also experienced recruitment problems (Buchan \& Seccombe 2003) and stress has also been linked to attrition among nursing students (Deary et al. 2003). Given the impact of stress in the nursing profession, it is imperative that attempts are made to understand the factors that give rise to it and which are critical to good coping in nursing students. This is the first UK study attempts to consider the potential positive and negative effects of perceived stress on coping, well-being and satisfaction.

\section{The Study}

\section{Aim}

The aim of this study was to explore the relationship between sources of stress and psychological well-being and to consider how different sources of stress and coping resources might function as moderators and mediators on well-being.

The two research questions were addressed:

What is the relationship between sources of stress, rated both as a potential for eustress and distress, and well-being in nursing students? 
What moderating and mediating role do self-efficacy, control, support and coping style have between perceptions of stress and well-being?

\section{Design}

A questionnaire-based study was carried out on data collected in 2008. Well-being was operationalised through measures on the General Health Questionnaire (Goldberg, 1978) and course and career satisfaction. The Transactional model of stress underpinned the assumptions tested. The model allows for a stressor to be rated in terms of its potential negative effects (distress) and its positive effects (eustress). Both were measured along with some important coping resources - self-efficacy, control, support and coping style - and the effect they had as moderators and mediators between the appraisal of sources of stress and their effect on well-being.

\section{Participants}

A convenience sample of 280 nursing students were invited to take part by the lead researcher at the start of a course lecture and $171(61 \%)$ consented. The inclusion criteria were students from all nursing specialisms in one institution in the final year of their programme. For age there were 15 missing values and for sex 20 missing values. For the remaining participants, 32\% $(n=50)$ were under $21 ; 40 \%(n=62)$ were $22-30 ; 23 \%(\mathrm{n}=36) 31-40$ and $5 \%$ 41-50 $(\mathrm{n}=8)$; and $87 \%$ were female $(\mathrm{n}=136)$ and $9 \%$ male $(n=15)$.

\section{Measures}

Index of Sources of Stress in Nursing (ISSN, Gibbons et al. 2009a, b)

This instrument consisted of 29 items measuring sources of stress in three factors learning and teaching, placement related and course organisation demands and were followed by items measuring support. A continuous response scale was used, with each item rated twice - once from its perceived distress, called a 'hassle', and once from its perceived eustress, called an 'uplift'. A non-applicable option was also included. A rating scale from 0-5 was used, 0 indicating that it was no source and 5 an extreme source of distress or eustress. 
This was followed by four items generated by one of the authors measuring context and dispositional control and a further four measuring course and career satisfaction. Respondents answered the support, control and satisfaction items on a five point Likert response scale from strongly agree to strongly disagree. All these items had earlier undergone reliability and validity analyses: Cronbach's alpha for these item groups as factors for control, support and satisfaction exceeded .7 and they were judged to have face validity.

The three hassle and uplifting factors and the support factor had been subjected to an exploratory and later confirmatory factor analyses (Gibbons et al., 2009a, 2009b). The exploratory factor analysis on the support items showed they loaded well on to one factor, explaining $53.4 \%$ of the variance in hassles ratings and $63.3 \%$ in uplifting ratings.

Generalized Self-Efficacy Scale (Schwarzer, 1992)

This scale consists of ten items and participants respond on a 4-point scale from 'not at all true' to 'exactly true'. It is a context-free measure of self-efficacy and has been used in numerous studies, with Cronbach's alpha ranging from .75 to .91 , and its stability has been established in several longitudinal studies (e.g. Schwarzer, 1992; Schwarzer and Schroder, 1997)

\section{General Health Questionnaire (GHQ 12-item version) (Goldberg, 1978)}

This is an established measure of transitory distress. A scoring scale of $0,0,1,1$ was used, corresponding to the four response options per item, of which respondents select one. The response options refer to degrees of change in normal day-to-day functioning and emotional states. A total score of 3 or higher indicates 'caseness' or risk of developing a transitory stress-related illness. The internal validity and test-retest reliability of this version have been demonstrated to be adequate or good in numerous studies (Goldberg and Williams, 1988).

Marlowe-Crowne Social Desirability (10 item version) (Crowne and Marlowe, 1960) This measure required students to choose whether a series of statements were true or false for them. A score of 1 was given for each answer concordant with the scoring algorithm. The tool measures response tendency and was used to assess possible 
social desirability bias across the instrument. Adequate validity and reliability have been demonstrated across numerous studies (Crowne and Marlowe, 1960; and McCrae and Costa, 1983).

\section{Brief COPE (Carver, 1997)}

This 28-item scale measures a broad range of coping responses. The items are context- free and respondents answer on a 4-point scale from 'I usually don't do this at all' to 'I usually do this a lot'. Carver recommends that researchers using the instrument subject it to their own factor analysis. This was done in a previous study and four coping factors were identified - approach coping; avoidance coping; altering consciousness and seeking support. They explained 57.99\% of the variance in coping scores. Cronbach's alpha exceeded .8 for each factor and they were judged to have face validity (Gibbons, 2008).

The remaining items measured demographics.

\section{Data collection}

After being briefed during a course lecture on the project by the researcher, students interested in taking part were invited to attend a computer suite later that week. At that point the aims were reiterated along with the ethical considerations.

\section{Ethical considerations}

The study was approved by a university ethics committee. Participation was voluntary and students were told that they were free to leave at any time, that being involved would have no effect on course progression, and that confidentiality would be maintained at all times. The researcher was unknown to the students. This was important as it could have introduced a power dimension affecting students' decisions to participate.

\section{Data analysis}

The data were analysed using SPSS version 15.1 using hierarchical multiple regression analyses. The Transactional model of stress (Lazarus and Folkman, 1984) informed the order in which the variables were entered into the analyses. The sources 
of stress relating to primary appraisal were entered in block one along with measures on sex, age and social desirability. The secondary appraisal relates to coping resources, and coping and moderator factors were entered next: support rated as a hassle and as an uplift; the four cope factors; dispositional control, context control and self-efficacy. Entered in the final block were the moderators that had been identified following testing for interaction effects between each predictor and potential moderator variable.

To establish the moderators that were the result of interaction effects, separate regressions were carried out following the guidelines proposed by Baron and Kenny (1980). The three sources of stress factors and support as a hassle were combined individually with each of the moderator variables, i.e. with support as an uplift; with self-efficacy; with dispositional control and context control; and with each of the four cope factors. Those interaction variables that explained a statistically significant amount of variance in well-being were fed into the final block of the hierarchical multiple regression. If the moderator identified by this interaction process was the product of random error, it would be unlikely to explain a statistically significant amount of variance when tested in the final multiple regression analysis for each wellbeing measure.

The variables with the lowest Beta values were then removed one at a time and the regression analysis repeated until the final model was judged to be the most parsimonious, i.e. until the Adjusted R squared approximated the R squared with the greatest amount of variance explained. In each case, the assumptions for using regression were checked and confirmed. The regression coefficients table for the final model in each case is shown below. 


\section{RESULTS}

Table 1 Descriptive data and correlations between factors, support and well-being measures

Table 2 Multiple regression with General Health Questionnaire (GHQ)

The model explained $47.9 \%$ of the variance in GHQ scores. The Beta values in Table 2 indicate the amount of variance explained. As avoidance coping increased, so did GHQ scores. As support, self-efficacy, dispositional control and the interaction variable - 'learning and teaching hassles and self-efficacy' - increased, scores on GHQ decreased.

Gender was a statistically significant predictor of GHQ in block 1 but not in block 2 of the regression. Each of the different types of coping and self-efficacy found to be statistically significant in block 2 was separately tested as a possible mediator. Only self-efficacy was statistically significant when tested. Figure 1 shows the mediating effect of self-efficacy between gender and GHQ. Table 3 shows the mediated and unmediated values. 
Figure 1 Self-efficacy Mediator

Table 3 Unmediated and mediated values between gender (sex) and General Health Questionnaire (GHQ) 
The unmediated path in Table 3 suggests that gender is a strong predictor of GHQ being female was associated with higher GHQ score. However, Figure 1 suggests that self-efficacy might be the predictor that can explain this apparent relationship. When both gender and self-efficacy were tested in regressions, gender was no longer statistically significant (the unmediated path). 
Figure 2 - Slope Graph testing the interaction between self-efficacy and learning and teaching hassles on General Health Questionnaire (GHQ).

In relation to the predictor, 'learning and teaching hassles-self-efficacy', in Table 2, Figure 2 shows that when self-efficacy is low (the top line), as learning and teaching hassles increase, so too do GHQ scores. As learning and teaching hassles increase, for those average in self-efficacy (the middle line), there is a moderate increase in GHQ scores. However, for those high in Self-efficacy (the bottom line), increases in learning and teaching hassles did not lead to any increase in GHQ scores. This suggests that self-efficacy acts as a buffer, protecting the individual against the affects of this source of stress on well-being, as measured by GHQ. 
Table 4 Multiple regression with course and career satisfaction

The model explained $36.7 \%$ of the variance in scores on course and career satisfaction. The more Altering consciousness, possibly a type of avoidance, was used, the lower were scores for course and career satisfaction. Similarly, the more placement-related demands were perceived as distressing, the lower were scores for course and career satisfaction. This was true of the two moderators. For the remaining predictors, statistically significant positive correlations were observed. 
Figure 3 - Slope Graph testing the interaction between dispositional control and course organisation hassles on course and career satisfaction.

In relation to the predictor 'Course organization hassles-Dispositional control', in Table 4, Figure 3 shows that when Dispositional control is high (the top line), as course organisation hassles increase, course and career satisfaction decrease. When Dispositional control is average, (the middle line), as course organisation hassles increase, course and career satisfaction show a moderate increase. When Dispositional control is low (the bottom line), as course organisation hassles increase, career and course satisfaction increase. 


\section{DISCUSSION}

This study represented an attempt to explore the sources of stress that are likely to contribute not just to distress but to eustress and to look at the relationship between sources of stress and well-being. Most earlier research with nursing students only explored stress as a potential for distress, and not eustress. This is the first study to explore the role of coping and self-efficacy not just as a predictor of well-being and satisfaction, but in terms of the extent to which these predictors might have a moderating and mediating role with perceived sources of stress as a potential for eustress as well as distress.

\section{Study limitations}

There were some limitations to the study. It relied on self-reported responses and respondents were final year students. These were selected because they had more academic and clinical experience to draw on, but that very experience would be likely to affect their appraisals and responses compared to students earlier in their studies. A longitudinal methodology, beginning with first year students, would negate this problem and the weaknesses associated with the cross-sectional design used here.

\section{Correlations between predictor variables}

Correlations between the predictors - sources of stress and coping resources and GHQ (Table 1) - support the assumptions of the transactional model (Lazarus and Folkman, 1984). As the factors - learning and teaching demands, placement demands and course organization demands - rated as hassles increased, so did GHQ scores. When the factors were rated as uplifts, increased GHQ scores fell.

Whilst there were fewer statistically significant correlations with course and career satisfaction (Table 1), those that were statistically significant concerned placement demands and not course organisation or learning and teaching. This suggests that placement experiences play a critical role in students' sense of satisfaction. So too does the quality of support available: overall, the more support was rated as a hassle, the poorer were scores for well-being. The more support was rated as an uplift, the healthier were well-being measures. These results and those for correlates with control and different types of coping suggested that a multiple regression analysis was appropriate. 


\section{General Health Questionnaire}

As shown in Table 2, learning and teaching demands, when reported as a hassle but not an uplift, explained a statistically significant variance in GHQ scores. An anomalous finding was that while sources of support, when rated as a hassle or potential distress, did explain a statistically significant variance in GHQ scores, the relationship was negative - the more support was rated as a hassle, the lower or healthier were the scores on GHQ. It is possible that the less a given coping resource is used, the more a different coping resource is used; it might be that good coping in another area not measured here explained this result. It might also be that,while some of the sources of support were rated as a hassle, the mere presence of support might have a beneficial effect (accounting for the lower corresponding scores on GHQ). Karasek and Theorell (1990) call this the additive effect. It is important also to be aware that experiences and relationships outside the course also contribute to GHQ.

\section{Mediation}

In terms of evidence of mediation (Figure 1 and Table 3), the results suggest that gender is a strong determinant of levels of self-efficacy, and that self-efficacy, in turn, is an important influence on psychological health, as measured by the GHQ. This suggests that self-efficacy plays an important mediating role in explaining the apparent relationship between gender and GHQ score.

\section{Moderation}

Ratings of learning and teaching as a hassle and measures on self-efficacy both separately explained a statistically significant amount of variance in GHQ scores. However, as Figure 2 illustrates, as a combined interaction they explained an additional amount of variance. The negative Beta value reported in Table 2 suggests that, while there was some benefit to having a strong self-efficacy in general (as indicated by the statistically significant variance it explained in GHQ scores when tested alone), the results on moderation showed that strong self-efficacy was particularly beneficial for those scoring high in learning and teaching hassles. Being efficacious not only means that stressors are less likely to be perceived as distressing, but also indicates a stronger belief in personal coping abilities. 


\section{Course and career satisfaction}

Altering consciousness coping accounted for the largest variance in course and career satisfaction: as it increased, lower scores were reported for course and career satisfaction. This type of coping included drug and alcohol use and meditative and religious practices. It might be that this type of coping was an expression of avoidance coping and, as this increased, career and course satisfaction decreased. Similar results were observed in a longitudinal study by Gibbons (2008), and the same conclusion might apply: that is, if an ineffective coping strategy is used, albeit infrequently, this can have an adverse affect on well-being. There is considerable evidence here and more broadly across the literature on nurses and nursing students that avoidance coping is ineffective coping (Lazarus and Folkman, 1987; Hamill, 1995: Chang et al. 2006).

Placement-related demands and course organisation demands, when rated as a hassle or potential for distress, were also predictors of course and career satisfaction. The more placement-related experiences were rated as a source of distress, the lower were the scores on course and career satisfaction. However, the more course organisation demands were rated as a hassle, the higher were the ratings for course and career satisfaction. These were final year students and they were experienced and used to the range of course organisational issues that would be part of this and indeed any other course of study. This finding, whilst on the face of it counterintuitive, might reflect reduced frustration with course organisation hassles compared with that of students earlier in their studies, who might have higher expectations. The former students might still recognise course demands that are a hassle, but they are less affected by them in terms of overall satisfaction.

\section{Control}

As context control increased, so did course and career satisfaction. This suggests that when students feel a greater sense of control in the learning context e.g. related to giving presentations, writing essays, portfolios and critical reviews, and in the placement learning context in exercising clinical skills, the more satisfied they are with the course and with nursing as a career. 


\section{Moderation}

Figure 3 reveals that when course organisation hassles and dispositional control were combined as an interaction variable, they explained a statistically significant variance in course and career satisfaction. Those high in dispositional control appear to be frustrated more by course demands that are rated as a potential source of distress compared to those moderate or low in dispositional control. This type of control is generally regarded as an indicator of effective coping (e.g. Lindop, 1999, AntaiOntong, 2002), but here it was not; it seems that those high in this tendency are frustrated more by experiences where they are unable to express this tendency. It is not that they cannot cope, rather that they may react more strongly to repeated experiences where it is difficult for them to exercise this disposition, such as in relation to cancelled classes, variability in tutor style, and having to listen to other students making presentations in class.

Many of the anticipated predictors (self-efficacy, dispositional control, support uplifts and placement uplifts) were positively related to measures of psychological health and explained a statistically significant variance in well-being. Avoidance coping and the hassle factors were predictors of less healthy well-being. However, many of the anticipated predictors, such as learning and teaching uplifts, course organisation uplifts and approach coping were not.

It is not surprising that avoidance coping was such a strong predictor, although its low mean compared to other types of coping (Table 1) indicates the strong adverse affect it can have, even when used infrequently. It could be inferred that the more avoidance coping was used, the less approach coping was, and that more approach coping would lead to healthier well-being scores, but this was not the case. This may indicate that the benefits of approach coping take longer to come to fruition. However, it was items from the Brief Cope that made up this factor (Carver, 1997). These are context-free and relate to general coping; while avoidance coping might be a tendency that is apparent across different situations, this may be less true for approach coping, e.g. a nursing student can develop the clinical skills to engage in active coping in some contexts but not others. 
Course organisation features relate to the smooth running of the course, and it is more likely that they will contribute to distress when those features are rated as ineffective, and less likely that they will be rated as a source of eustress when those features are acceptable. In a sense, course organisation demands are analogous to Herzberg's hygiene factors in his theory of motivation (1959). These are features that, if present, do not increase motivation or satisfaction but, if absent, contribute to dissatisfaction. This could explain why course organisation demands, as a potential for eustress, was not a predictor of GHQ or satisfaction. That course organisation as a factor was statistically significant with other factors (e.g. Figure 3) does suggest, however, that the items that make up this factor remain in the instrument but be rated on the hassles scale only.

It was anticipated that learning and teaching as an uplift would predict healthy wellbeing measures, but this was not found. This may reflect the point that the well-being measures may be more responsive to distress than eustress. It may be that, as the course nears its completion students are prioritizing course demands, and that focusing on this means that experiences of good teaching have less of an impact. They have become accustomed to good teaching and therefore find it less uplifting. It might also be that the quality of learning and teaching has changed because of cumulative demands on the teaching staff.

The evidence of mediation confirms some earlier findings, for example that selfefficacy was the mediator representing the indirect relationship between gender and GHQ score (Jones and Johnston, 1999). Nursing is a relatively new academic discipline; its population is largely female and in most UK universities it is taught largely by staff from a nursing background. Not all have higher degrees or are research active. There is evidence that women more than men are likely to report lower self-efficacy (Zhang et al. 2001, Ferguson, 2008), and this may inadvertently come to be reinforced by staff because of a school's relatively recent academic standing and because of the background of most teaching staff. This trend could be reversed if teaching staff engaged in more research, perhaps starting by researching and testing the pedagogy of what they teach, and if they make more opportunities to promote the status of nursing as a profession and a profession that also includes opportunities to engage in research. 


\section{CONCLUSION}

All students can improve their coping, and initiatives aimed at bolstering student selfefficacy, control and support would help, for example through induction, social, and learning and teaching initiatives involving peer interaction, and through support offered by personal tutors, tutors and lecturers.

Self-efficacy could be bolstered by validating student learning orally in response to contributions in teaching sessions; in feedback given during and after simulated and real clinical experiences, and in written comments made on students' work.

Problem-based learning has been shown to be effective, not just for pedagogic reasons but because of the sense of control and empowerment students experience as well as the support benefits that come from co-operative learning (Dunlap, 2005).

The evidence here on avoidance coping shows that ineffective strategies can have adverse effects, even when used infrequently. This could usefully be conveyed to students, along with strategies to promote effective coping. It could be done through standalone workshops early in the course, as well as being built into the psychology component of nursing programmes.

Approach coping was not found to be predictive of GHQ or satisfaction. This is not to question the efficacy of this coping strategy, and not to argue against its inclusion in stress management initiatives. Rather it is to recognize that its benefits are likely to become evident in the medium- to long-term, and that other strategies, such as promoting support, control and self-efficacy, are likely to have more immediate benefits.

Teachers should not lose sight of the fact that changes, especially small changes, in how they interact with students in their teaching and pastoral roles can have dramatic effects. Becoming or remaining aware of one's coping style and the small positive changes possible could contribute to improvements in student well-being and learning. 
The evidence that uplifts as well as hassles are important predictors suggests that attempts to understand sources of stress must take both into account in order to understand the main influences on student well-being. This is critical in higher education because of its implications for student learning and attrition, and because nursing student' performance has a direct bearing on their fitness to practice and on patient safety. 


\section{REFERENCES}

Andrew, S. (1998) Self-efficacy as a predictor of academic performance in science. Journal of Advanced Nursing, 27, 596-603

Antai-Ontong, D., (2002). Culture and traumatic events. Journal of the American Psychiatric Nurses Association 8, 203-208.

Baron, R. M., \& Kenny, D. A. (1986). The moderator-mediator variable distinction in social psychological research: Conceptual, strategic, and statistical considerations. Journal of Personality and Social Psychology, 51, 1173-1182.

Beck D.L. and Srivastava R. (1991). Perceived level and sources of stress in Baccalaureate nursing students. Journal of Nursing Education 30 (3), 127-133.

Boey, K. W. (1999) Distressed and stress resistant nurses. Issues in Mental Health Nursing, 19, 33-54.

Carver, CS. (1997) You want to Measure Coping But Your Protocol's Too Long: Consider the Brief COPE. International Journal of Behavioral Medicine. 4 (1), 92100.

Ceslowitz, S.B., 1989. Burnout and coping strategies among hospital staff nurses. Journal of Advanced Nursing 14 (7), 553-558.

Chang, E.M., Daly, J., Hancock, K.M., Bidewell, J.W., Johnson, A., Lambert, V., Lambert, C., (2006). The relationships among workplace stressors, coping methods, demographic characteristics and health in Australian nurses. Journal of Professional Nursing 22 (1), 30-38.

Crowne D.P. and Marlowe D.A. (1960). A new scale of social desirability independent of psychopathology. Journal of Consulting Psychology 24, 349-354. 
Deary, I. J., Watson, R. and Hogston, R. (2003). A Longitudinal cohort study of burnout and attrition in nursing students. Issues and innovations in nursing education. Journal of Advanced Nursing, 43 (1), 71-81.

Dunlap, J. C. (2005). Problem-based learning and self-efficacy: How a capstone course prepares students for a profession. Educational Technology Research and Development, 53(1), 65-85.

Ferguson, P. (2008) Transcultural self-efficacy in graduating nursing students. Dissertation Abstracts International Section A: Humanities and Social Sciences, 68 (9-A).

Folkman, S. (1997). Positive psychological states and coping with severe stress. Social Sciences and Medicine. Vol. 45, 8, 1207-1221.

Gibbons, C. (2008) Measuring Stress and Eustress in Nursing Students. PhD Thesis, Queen's University Belfast, UK.

Gibbons, C., Dempster, M. and Moutray, M. (2009a), Surveying nursing students on their sources of stress: A validation study, Nursing Education Today. Vol. 29, (8), 867-872.

Gibbons, C., Dempster, M. and Moutray, M. (2009b), Index of sources of stress in nursing students: a confirmatory factor analysis. Journal of Advanced Nursing, Vol. 65 (5), 1095-1102.

Goldberg, D.P. (1978). Manual of the General Health Questionnaire, NFER-Nelson, Windsor.

Goldberg D. and Williams P. (1988). A User's Guide to the General Health Questionnaire. NFER-Nelson, Windsor.

Greenglass, E. R. \& Burke, R. J. (2000) The relationship between hospital restructuring, anger, hostility and psychosomatics in nurses. Journal of Community and Applied Social Psychology, 10, 155-161. 
Hamill C. (1995). The phenomenon of stress as perceived by Project 2000 student nurses: a case study. Journal of Advanced Nursing 21, 528-536.

Heaman D. (1995) The quieting response (QR): a modality for reduction of psychophysiologic stress in nursing students. Journal of Nursing Education 34(1), 510.

Herzberg, Frederick 1959, The Motivation to Work, New York, John Wiley and Sons.

Howard, D. A. (2001). Student nurses' experience of Project 2000. Nursing Standard, 15(48), 33-38.

Jack B. (1992) Ward changes and stress in student nurses. Nursing Times 88 (10), 51.

Jones M.C. and Johnston D.W. (1997). Distress, stress and coping in first-year student nurses. Journal of Advanced Nursing 26, 475-482.

Jones, M. C., and Johnston, D. W. (1999). The derivation of a brief student nurse stress index. Work and Stress, 13(2), 162-168.

Karasek R. and Theorell T. (1990). Healthy Work: Stress, Productivity, and the Reconstruction of Working Life. Basic Books, New York.

Kipping, C. J. (2000). Stress in mental health nursing. International Journal of Nursing Studies, 37, 207-218.

Kirkland, M. L. S. (1998). Stressors and coping strategies among successful female African American baccalaureate nursing students. Journal of Nursing Education, 37(1), 5-12.

Lambert, V.A., Lambert, C.E., Ito, M., (2004). Workplace stressors, ways of coping and demographic characteristics as predictors of physical and mental health of Japanese hospital nurses. International Journal of Nursing Studies 41 (1), 85-97. 
Lazarus R.S. \& Folkman S. (1984) Stress, Appraisal, and Coping. Springer, New York.

Lazarus, R.S. and Folkman, S. (1987). Transactional theory and research on emotions and coping, European Journal of Personality 1, 141-170.

Laschinger H.K.S. (1996) Undergraduate nursing students' health promotion counselling self-efficacy. Journal of Advanced Nursing 24, 36-41.

Lazarus, R.S. and Folkman, S. (1987). Transactional theory and research on emotions and coping, European Journal of Personality 1, 141-170.

Lindop, E., (1999). A comparative study of stress between pre and post project 2000 students. Journal of Advanced Nursing 29 (4), 967-973.

Lo, R. (2002). A longitudinal study of perceived level of stress, coping and selfesteem of undergraduate nursing students: An Australian case study. Journal of Advanced Nursing 39(2), 119-126.

Lucas, M. D., Atwood, J. R. \& Hagaman, R. (1993) Replication and validation of anticipated turnover model for urban registered nurses. Nursing Research, 42, 29-35.

Mahat, G. (1996). Stress and coping: First-year Nepalese nursing students in clinical settings. Journal of Nursing Education, 35(4), 163-169.

Mahat, G. (1998). Stress and coping: Junior baccalaureate nursing students in clinical settings. Nursing Forum 33(1), 11-19.

McCrae, R. R. and Costa, P. T. (1983), "Social Desirability Scales: More Substance than Style," Journal of Consulting and Clinical Psychology, 51, 882-888.

Parkes K.R. (1994) Personality and coping as moderators of work stress processes: models, methods and measures. Work and Stress 8(2), 110-129. 
Payne, N. (2001) Occupational stressors and coping as determinants of burnout in female hospice nurses. Journal of Advanced Nursing, 33, 396-405.

Pryjmachuk, S. and Richards, D. A. (2007) Predicting stress in pre-registration nursing students. British journal of Health Psychology, 12, 125-144.

Rhead, M. M. (1995). Stress among student nurses: Is it practical or academic? Journal of Clinical Nursing 4, 369-376.

Schafer, W. (1992). Stress Management for Wellness. Second Edition, Harcourt Brace Janovich, Fort Worth. p.14

Schaubroeck, J. and Merritt, D.E. (1997). Divergent effects of job control on coping with work stressors: The key role of self-efficacy. Academy of Management Journal 40, 3, 738-754.

Schwarzer, R. (Ed.) (1992). Self-Efficacy: Thought Control of Action. Washington, DC: Hemisphere.

Schwarzer, R and Schroder, K. E. E. (1997). Effects of Self-efficacy and social support on postsurgical recovery of heart patients. Irish Journal of Psychology, 18, 88-103.

Snape, J., and Cavanagh, S. (1995). The problems facing students of nursing. Education Today, 45(2), 10-15.

Tully, A. (2004). Stress, sources of stress and ways of coping among psychiatric nursing students. Journal of Psychiatric and Mental Health Nursing 11, 43-47

Van der Doef, M. and Maes, S. (1999), The Job Demand-Control(-Support) model and psychological well-being: a review. Work and Stress 13, 87-114. 
Wu S., Zhu W., Wang Z. , Wang M. \& Lan Y. (2007) Relationship between burnout and occupational stress among nurses in China. Journal of Advanced Nursing 59(3), 233-239

Zhang Z-x, Luk W, Arthur D \& Wong T (2001) Nursing competencies: personal characteristics contributing to effective nursing performance. Journal of Advanced Nursing 33, 467-474. 
Table 1 Descriptive data and correlations between factors, support and well-being measures

\begin{tabular}{|c|c|c|c|c|}
\hline & Well-b & g measures & & \\
\hline Factor/Predictor & GHQ & $\begin{array}{l}\text { Course and } \\
\text { career } \\
\text { satisfaction }\end{array}$ & Mean & Standard Deviation \\
\hline $\begin{array}{l}\text { Learning and } \\
\text { teaching hassles }\end{array}$ & $.308^{*}$ & -.121 & 2.776 & .815 \\
\hline $\begin{array}{l}\text { Learning and } \\
\text { teaching uplifts }\end{array}$ & $-.292 * *$ & .133 & 1.901 & .967 \\
\hline $\begin{array}{l}\text { Placement-related } \\
\text { hassles }\end{array}$ & $.225 * *$ & $-.228 * *$ & 2.241 & .916 \\
\hline $\begin{array}{c}\text { Placement-related } \\
\text { uplifts }\end{array}$ & $-.158 *$ & $.184 *$ & 2.885 & .724 \\
\hline $\begin{array}{c}\text { Course } \\
\text { organization } \\
\text { hassles }\end{array}$ & $.226 * *$ & .020 & 3.972 & .647 \\
\hline $\begin{array}{c}\text { Course } \\
\text { organization } \\
\text { uplifts }\end{array}$ & $-.168 *$ & .043 & 2.442 & .756 \\
\hline Support hassles & $.173^{*}$ & -.096 & 1.667 & .969 \\
\hline Support uplifts & $-.246^{* *}$ & $276^{* *}$ & 3.588 & .907 \\
\hline Self-efficacy & $-.411 * *$ & .152 & 2.918 & .811 \\
\hline $\begin{array}{l}\text { Dispositional } \\
\text { control }\end{array}$ & $-.453 * *$ & -.054 & 3.317 & .815 \\
\hline Context control & $-.417 *$ & $.294 * *$ & 2.918 & .674 \\
\hline Approach coping & .149 & $-.229 * *$ & 2.299 & .659 \\
\hline Avoidance coping & $-515 * *$ & $-.273 * *$ & 1.773 & .563 \\
\hline $\begin{array}{c}\text { Altering } \\
\text { consciousness }\end{array}$ & .114 & $-.352 * *$ & 1.627 & .567 \\
\hline Seeking support & .052 & -.079 & 2.226 & .704 \\
\hline
\end{tabular}


Table 2 Multiple regression with General Health Questionnaire (GHQ)

\begin{tabular}{|c|c|c|c|c|c|c|}
\hline \multirow[t]{2}{*}{ Model } & & \multicolumn{2}{|c|}{$\begin{array}{c}\text { Unstandardized } \\
\text { Coefficients } \\
\end{array}$} & \multirow{2}{*}{$\begin{array}{c}\text { Standardized } \\
\text { Coefficients } \\
\text { Beta }\end{array}$} & \multirow[b]{2}{*}{$\mathrm{t}$} & \multirow[b]{2}{*}{ Sig. } \\
\hline & & $\mathrm{B}$ & Std. Error & & & \\
\hline & (Constant) & .408 & .307 & & 1.329 & .186 \\
\hline & $\begin{array}{l}\text { Learning and Teaching } \\
\text { Hassles }\end{array}$ & .076 & .030 & .229 & 2.524 & .013 \\
\hline & $\begin{array}{l}\text { Learning and Teaching } \\
\text { Uplifts }\end{array}$ & -.023 & .031 & -.062 & -.730 & .467 \\
\hline & Placement-related Uplifts & .054 & .034 & .124 & 1.589 & .114 \\
\hline & Social Desirability & .173 & .121 & .095 & 1.437 & .153 \\
\hline & Gender & .072 & .058 & .084 & 1.244 & .216 \\
\hline & Age & .040 & .021 & .125 & 1.852 & .066 \\
\hline & Avoidance Coping & .128 & .037 & .266 & 3.447 & .001 \\
\hline & Support Hassles & -.067 & .028 & -.239 & -2.360 & .020 \\
\hline & Support Uplifts & -.090 & .030 & -.294 & -3.012 & .003 \\
\hline & Self-Efficacy & -.201 & .055 & -.264 & -3.671 & $<.001$ \\
\hline & Dispositional Control & -.058 & .024 & -.182 & -2.427 & .017 \\
\hline & $\begin{array}{l}\text { Learning and Teaching } \\
\text { hassles - Self-Efficacy } \\
\text { moderator }\end{array}$ & -.177 & .064 & -.179 & -2.771 & .006 \\
\hline & $\begin{array}{l}\text { Learning and Teaching } \\
\text { hassles - Avoidance } \\
\text { coping moderator }\end{array}$ & .071 & .044 & .112 & 1.616 & .109 \\
\hline
\end{tabular}

Dependent Variable: GHQ

$\mathrm{R}$ squared $=.526$, Adjusted $\mathrm{R}$ squared $=.479$ 
Figure 1 Self-efficacy Mediator

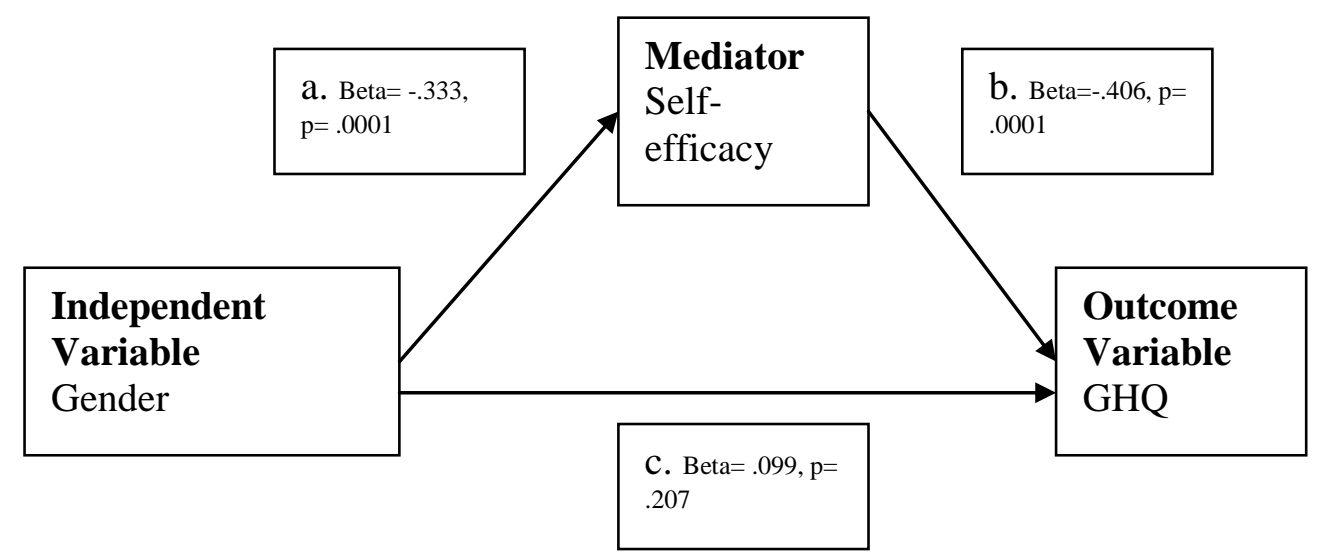


Table 3 Unmediated and mediated values between gender (sex) and General Health Questionnaire (GHQ)

\begin{tabular}{|l|l|l|}
\hline & Beta value & $\mathrm{p}$ value \\
\hline Unmediated path & .234 & .004 \\
\hline Mediated path & .099 & .207 \\
\hline
\end{tabular}

Figure 2 - Slope Graph testing the interaction between self-efficacy and learning and teaching hassles on General Health Questionnaire (GHQ).

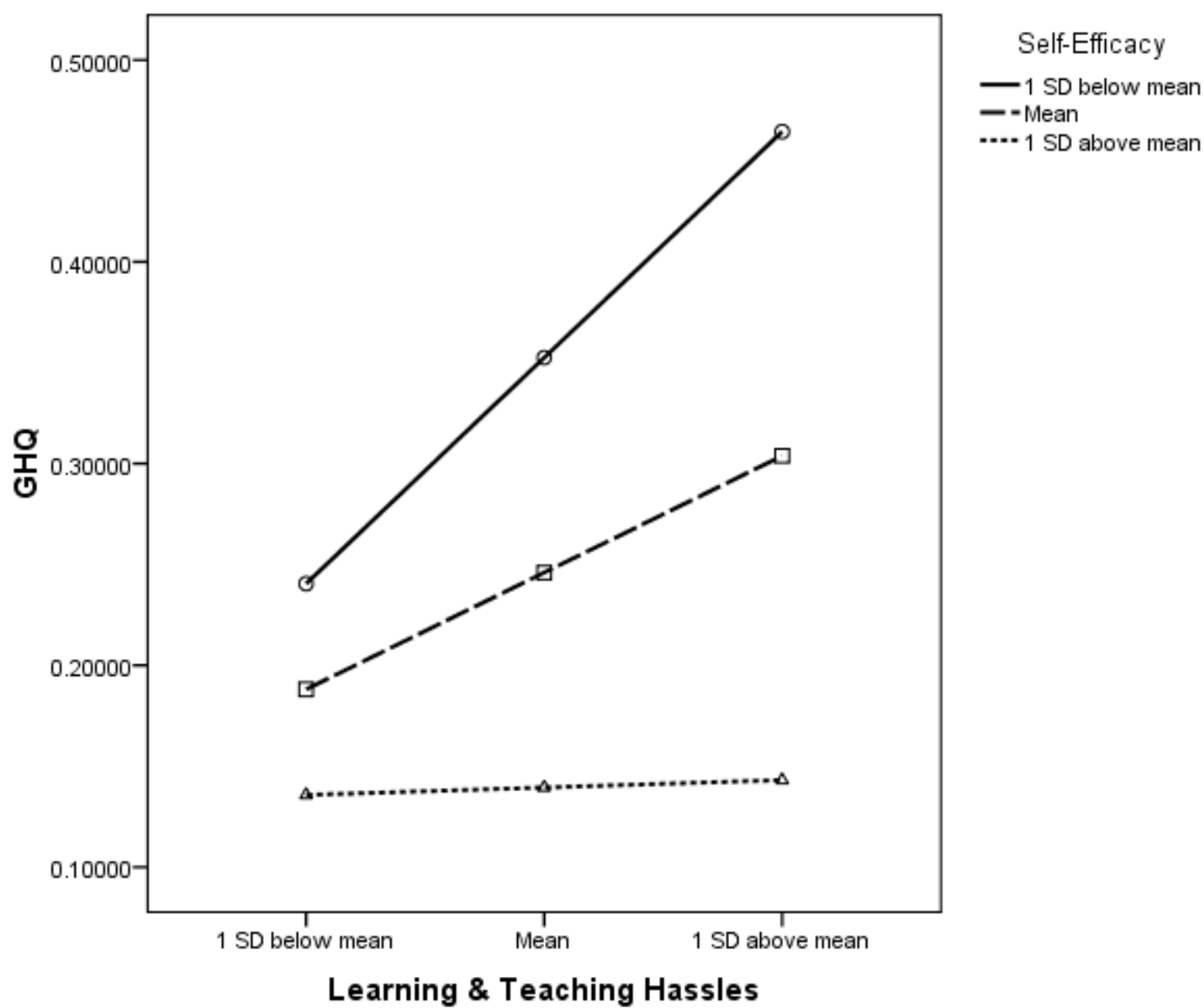


Table 4 Multiple regression with course and career satisfaction

\begin{tabular}{|c|c|c|c|c|c|c|}
\hline \multirow[t]{2}{*}{ Model } & & \multicolumn{2}{|c|}{$\begin{array}{l}\text { Un-standardized } \\
\text { Coefficients }\end{array}$} & \multirow{2}{*}{$\begin{array}{c}\text { Standardized } \\
\text { Coefficients } \\
\text { Beta }\end{array}$} & \multirow{2}{*}{$\mathrm{t}$} & \multirow{2}{*}{$\begin{array}{c}\text { Sig. } \\
\text { Std. Error }\end{array}$} \\
\hline & & B & Std. Error & & & \\
\hline & (Constant) & 1.972 & .622 & & 3.171 & .002 \\
\hline & Placement related Hassles & -.232 & .066 & -.269 & -3.505 & .001 \\
\hline & Course Organisation Hassles & .258 & .074 & .268 & 3.497 & .001 \\
\hline & Age & .126 & .064 & .138 & 1.966 & .051 \\
\hline & Social Desirability & .755 & .379 & .137 & 1.990 & .049 \\
\hline & Support Uplifts & .173 & .070 & .187 & 2.489 & .014 \\
\hline & Altering Consciousness & -.390 & .095 & -.279 & -4.106 & .001 \\
\hline & Context Control & .223 & .082 & .190 & 2.710 & .008 \\
\hline & $\begin{array}{l}\text { Course Organisation Hassles } \\
\text { Dispositional Control } \\
\text { Moderator }\end{array}$ & -.194 & .079 & -.162 & -2.438 & .016 \\
\hline & $\begin{array}{l}\text { Placement related uplifts } \\
\text { Seeking support moderator }\end{array}$ & -.209 & .109 & -.129 & -1.921 & .057 \\
\hline
\end{tabular}

a Dependent Variable: Course and Career Satisfaction

$\mathrm{R}$ squared $=.406$, Adjusted R squared $=.367$ 
Figure 3 - Slope Graph testing the interaction between dispositional control and course organisation hassles on course and career satisfaction.

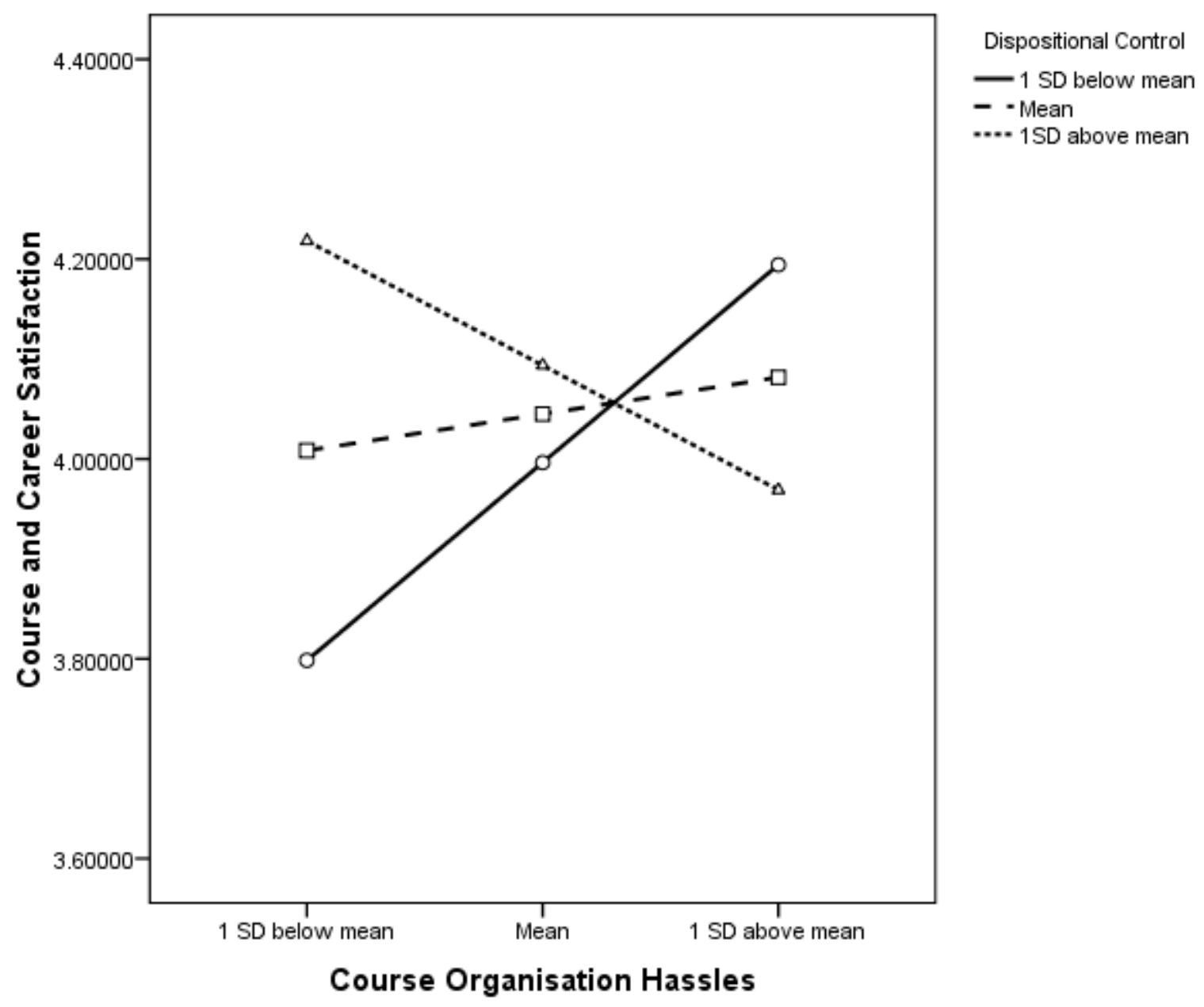

